\title{
METAMORFOSES DA POBREZA
}

\author{
A INVENÇÃO DA FAVELA: DO MITO DE ORIGEM A FAVELA.COM \\ de Licia do Prado Valladares. Rio de Janeiro: FGV, 2005.
}

AdALBERTO CARDoso

[1] Weber, M. Sobre a teoria das ciências sociais. Lisboa: Presença, 1974.

[2] Lakatos, I. Criticism and the growth of knowledge. Nova York: Cambridge University Press, 1970.

[3] Latour B. \& Woolgar, S. A vida de laboratório. A produção dos fatos científicos. Rio de Janeiro: Relume Dumará, 1997.

[4] Giddens, A.As conseqüências da modernidade. São Paulo: Editora da Unesp, 1991.

[5] Geertz, C.A interpretação das culturas. Rio de Janeiro: LTC, 1989.

[6] Gusfield, J. The culture of public problems. Chicago: University of Chicago Press, 1981.
Desde que Weber publicou o excepcional ensaio sobre a objetividade do conhecimento nas ciências sociais, ${ }^{1}$ sabemos que a sociologia não pode ser ciência positiva como a biologia ou a física. Ainda que a consolidação e reprodução de programas de pesquisa ${ }^{2}$ nessas ciências siga lógica semelhante à das ciências sociais, com interesses institucionalizados, disponibilidade de recursos e disputas políticas influenciando decisivamente o que será ou não estudado, e ainda que as práticas mesmas de pesquisa tampouco possam ser cabalmente distinguidas, ${ }^{3}$ a sociedade não é um ser em si à espera de decifração pelo método científico mais adequado. Ocorre que o discurso científico sobre a sociedade constitui seu ser. Ou, como diria Giddens, ${ }^{4}$ a ciência social é uma espécie de consciência reflexiva da sociedade, construindo com ela interpretações sobre si própria que, ao influir no curso das coisas, mudam esse objeto no momento mesmo em que pretende tê-lo decifrado. Desse ponto de vista, o objeto de estudo não é externo ao observador, que só pode agir, pensar, sentir e construir interpretações sobre o mundo social enquanto enclausurado nos horizontes culturais desse mesmo mundo.5 O horizonte do objeto é o horizonte do observador. O objeto, nessas condições, precisa ser construído, não sendo uma espécie de coisa que se impõe ao cientista, nem um problema em si mesmo cujos elementos constitutivos sejam independentes das intenções e perspectivas parciais do analista.

Este excelente A invenção da favela, de Licia Valladares, assume tal ponto de vista já no título. Borrando fronteiras disciplinares, o trabalho é um pouco de história das idéias e dos conceitos (como em Koselleck), um pouco de sociologia do conhecimento (como em Merton), um pouco de sociologia construtivista (como em Gusfield ${ }^{6}$ ) e um pouco de sociologia histórica (como em Elias), que procura desvendar as metamorfoses da favela carioca no imaginário de agentes do poder público, sanitaristas, urbanistas, cientistas sociais, militantes da Igreja Católica e outras confissões, jornalistas e outros que contribuíram, cada qual à sua maneira, para a transformação, ao longo de cem anos, da favela em problema social e, depois, em problema sociológico. Como, para a 
autora, o "pensamento de determinado autor só pode ser compreendido quando se leva em conta o seu tempo, origens de classe, características sociais, políticas e religiosas, além do contexto intelectual em que circulava e se inseria" (p.13), o livro é também um pouco de história do Brasil, que aparece como pano de fundo do teatro que realmente interessa, as representações sobre a favela. Nesse sentido, e em muitos outros, trata-se de obra original que vem preencher importante lacuna nos estudos sobre o tema no Brasil.

Embora o problema geral que interessa à autora não seja explicitado desde o início (na verdade, insidioso nas páginas iniciais, ele só se revela plenamente no final do texto, ali pela página 150), o livro de Licia Valladares pode ser lido como uma tentativa de recuperar o processo de consolidação, no ideário carioca e também nacional, de um conjunto de dogmas sobre a favela. A partir do que ela denomina mito fundador (situado no final do século XIX, quando os combatentes de Canudos fincam moradia no morro da Providência, mais tarde morro da Favella, reproduzindo ali os padrões habitacionais típicos do sertão nordestino e, com isso, fundando a visão dual que opunha "favela versus cidade", na esteira da dualidade "sertão versus litoral" típica das interpretações do Brasil de então), Valladares mostra em que medida as representações sucessivas sobre a favela como fenômeno social terminaram por consolidar, mesmo entre os cientistas sociais, o "dogma" de que a favela é diferente do asfalto. ${ }^{7}$ Sua lavra é cortante:

A academia vem insistindo em que a favela, inicialmente berço do samba [...], éhoje o reino do funke do rap. [...] Outrora sede do jogo do bicho,éagora identificada com território do tráfico de drogas [...]. Lugar onde até mesmo a própria política apresentaria uma forma diferente [...]. Assim, a favela condicionaria o comportamento de seus habitantes, em uma reativação do postulado higienista ou ecologista da determinação do comportamento humano pelo meio. (p.15o)

O segundo dogma, também com origem histórica,é de que a favelaé o lugar da pobreza, "o território urbano dos pobres" (p. 151). Essa associação decorre do mesmo mito de origem, já que os moradores do morro da Favella eram de fato miseráveis e para as favelas teriam acorrido, sempre, as populações pobres da cidade, migrantes ou não. Mas Valladares mostra que isso não é mais assim na maioria das favelas do Rio, ${ }^{8}$ que têm, sim, uma proporção grande de pessoas pobres mas que nem por isso são o território exclusivo da pobreza. Com a mesma linguagem cortante, ela afirma que "os pesquisadores não hesitam quando se trata de estudar os pobres: vão para a favela. [...] Transformada em campo, nela são estudados todos os fenômenos associados à pobreza e ao universo popular" (p.151), que no entanto não estariam confinados nas favelas, e sim dispersos por vastas regiões da periferia da região metropolitana do Rio de Janeiro. O terceiro dogma sustenta a "unidade da favela", quando
[7] Valladares faz interessante contraponto entre a visão de Canudos expressa por Euclides da Cunha em $O s$ sertões e as visões da emergente realidade da Favella no início do século XX (pp. 28-36), para concluir que a "imagem matriz da favela [como um outro mundo] já estava [...] construída e dada a partir do olhar arguto e curioso do jornalista/observador" (p.36).
[8] $\mathrm{Na}$ verdade, ainda nos anos 1960, Machado da Silva chamara a atenção para a existência de uma "burguesia favelada". Ver Machado da Silva, L. A. "A política na favela". Cadernos Brasileiros, Rio de Janeiro, vol. 9, no 3, maio-jun, pp. 35-47. 
[9] Segundo Valladares, o relatório do médico Victor Tavares Moura, de 1940 , teria sido o primeiro a evidenciar a complexidade da favela, desmistificando a visão corrente de que as favelas eram "o lugar da criminalidade, marginalidade e desorganização social" (p. 57).

[10] É o caso, entre outros, de Valla, V.V. (org.).Educação e favela. Políticas para as favelas do Rio de Janeiro, 19401980. Petrópolis: Vozes, 1986, e Burgos M.B. “Dos parques proletários ao favela-bairro: as políticas públicas nas favelas do Rio de Janeiro". In: Alvito, M. e Zaluar, A. (orgs.) Um século de favela. Rio de Janeiro: Editora da FGV, 1998, pp. 25-6o. na verdade as favelas apresentam e sempre apresentaram diferenças marcantes entre si e mesmo internamente, diferenças historicamente negligenciadas por boa parte das políticas públicas de saneamento, remoção ou urbanização desses espaços urbanos. ${ }^{9}$

A edificação desses dogmas ao longo de cem anos de favelização no Rio é reconstituída por Valladares por meio de uma periodização que obedece a lógica própria, diversa daquela proposta pela maior parte da literatura sobre o tema e que combina, de modo geral, etapas do processo de crescimento das favelas com a natureza das políticas públicas voltadas para o enfrentamento do fenômeno. ${ }^{10} \mathrm{~A}$ autora propõe três grandes períodos, analisados nos três capítulos do livro. O primeiro vai da gênese da Favella até o final dos anos 1940, o segundo cobre os anos 1950 e 1960 e o terceiro, os anos 1970 a 2000 . Desde logo é bom marcarque essa periodização é um tanto arbitrária, porque não leva em conta os dados que a própria autora mobiliza no capítulo 3 , segundo os quais $80 \%$ dos 838 títulos analisados para a produção do livro foram publicados de 1970 a 2000 . Como o interesse é reconstituir as metamorfoses na representação das favelas, há um desequilíbrio evidente na quantidade de registros analisados em cada período, o que tem conseqüências importantes para a coerência metodológica da análise. Os dois primeiros capítulos, por exemplo, dão ênfase a determinadas pessoas ou instituições-chave na construção do ideário sobre as favelas, o que leva a um relato que acentua a trajetória pessoal e as redes sociais que levaram tal ou qual personagem a se aproximar do fenômeno e produzir tal ou qual reflexão pessoal, que repercutiu desta ou daquela maneira no ambiente onde atuou, contribuindo assim para a construção ou desconstrução dos dogmas sobre a favela.Já o terceiro capítulo é sobretudo uma análise quantitativa da tendência geral da produção acadêmica, onde os autores e sua trajetória desaparecem inteiramente. Não me parece suficiente o argumento de que a produção tornou-se volumosa demais para uma análise caso a caso. Alguns grupos de pesquisa, essenciais ao debate atual sobre o tema, poderiam ter sido identificados, com a reconstituição de sua trajetória e o impacto de sua produção, sem prejuízo da análise estatística mais geral. Isso daria maior unidade metodológica ao tratamento do material empírico tão judiciosamente coletado por Valladares e sua equipe no Urbandata-Brasil.

Esse comentário não desmerece o trabalho realizado, já que mesmo a avaliação agregada da enorme produção dos últimos vinte anos é de grande valia para os pesquisadores desse campo. A análise estatística está apenas em descompasso com a empreendida nos dois primeiros capítulos. Aqui descobrimos a importância dos relatos de jornalistas como Benjamin Costallat ou de cronistas como João do Rio na construção da imagem da favela como "um outro mundo", "um caminho de cabras" (p. 31), o espaço da "miséria indolente" (p.35). Descobrimos o processo de transformação da favela em problema social a ser resolvido (patologia social a ser combatida) e sua população, controlada.Vemos a 
lenta mudança de perspectiva sob Vargas, quando o Código de Obras de 1937, elaborado pelo prefeito nomeado pelo ditador, propunha a remoção das favelas e a substituição por novos alojamentos "de acordo com as normas de salubridade" (p.53), perspectiva que perderia importância com o passar dos anos (em parte com a entrada da Igreja Católica e dos assistentes sociais na cena onde o ideário sobre as favelas se constituía), retornando depois de 1948 com Carlos Lacerda e sua Batalha do Rio, voltada para a remoção de favelas.

O papel da Igreja Católica, aliás, tem espaço destacado na análise de Valladares. Instituição decisiva na história política e social brasileira, ${ }^{11}$ está presente como um dos agentes responsáveis por "problematizar" a favela, primeiro em chave conservadora e caritativa (antes dos anos 1950), depois respondendo às mudanças que desaguariam no Segundo Concílio do Vaticano e, mais tarde, na Teologia da Libertação. No Rio as mudanças na Igreja seriam antecipadas por uma figura emblemática, dom Elder Câmara e sua Cruzada de São Sebastião, criada em 1955 para dar "solução racional, humana e cristã ao problema das favelas do Rio de Janeiro", o que resultaria, na prática, num movimento pela sua urbanização (p.77). Um dos subprodutos dessa cruzada foi a geração de informação mais detalhada sobre diversas favelas do Rio, coisa que o Censo Demográfico de 1950, primeiro a identificar esse espaço de habitação popular, não permitia.

Nesse pormenor, tão ou mais importante foi a vinda de padre LouisJoseph Lebret ao Brasil, trazendo consigo o movimento Économie et Humanisme, voltado para a promoção dos povos e o desenvolvimento econômico. Lebret tem lugar de destaque na análise de Valladares, ocupando mais de uma vintena de páginas em razão do papel central na produção de conhecimentos inovadores e sistemáticos sobre as favelas do Rio, presentes no relatório Aspectos humanos da favela carioca, publicado em 1960 e dirigido por José Arthur Rios, que, segundo o próprio autor, cruzou o método monográfico de Lebret e a ecologia humana da Escola de Chicago (p.101) para produzir um estudo que ia de encontro aos dogmas de então, como frisa Valladares. A pesquisa, financiada pelo jornal $O$ Estado de S. Paulo, ${ }^{12}$ teria inovado em método e resultados, já que as favelas foram apresentadas como realidades heterogêneas e internamente diferenciadas, análises que teriam sido "esquecidas" por muitos pesquisadores atuais (p. 102) que continuariam a difundir os dogmas que a autora quer desmontar.

Lebret não foi o primeiro nem o último estrangeiro a se interessar pelas favelas e a contribuir para a construção de seus muitos significados. Houve vários agentes importantes na delimitação dos horizontes de significação do universo favelado carioca: viajantes no começo do século XX que compartilhavam da imagem da favela como chaga a ser removida; voluntários da paz (os Peace Corps do governo norte-americano) que contribuíram para difundir a idéia da favela no singular, nos anos 1960; brasilianistas de diversas estirpes que negaram ou confirma-
[11] O pensamento católico foi decisivo para definir a ideologia corporativista autoritária no Brasil, e embalou Oliveira Vianna e Alceu Amoroso Lima igualmente, como mostrou Werneck Vianna (Liberalismo e sindicato no Brasil. 2a ed. rev.Belo Horizonte: Editora da UFMG, 1999). Esteve nas ruas de São Paulo com a Marcha da Família com Deus Pela Liberdade (Codato A. N. \& Oliveira, M. R. de. "A marcha, o terço e o livro: catolicismo conservador e ação política na conjuntura do golpe de 1964 ". Revista Brasileira de História, vol.24, no 47,2004 , pp. 271-302), movimento conservador contra Jango. Mas fez sua opção pelos pobres depois do Segundo Concílio Vaticano, e a Teologia da Libertação foi importante força de resistência ao regime de 1964, como mostram Delgado (L. de A. N. “Ásperos tempos catolicismo, direitos humanos e direitos sociais. Brasil anos sessenta e setenta".In.:Cabrera, O. (org.).Experiências e memória. Goiânia, Ed. Vieira, 2001.) e Serbin (K.Diálogos na sombra: bispos e militares, tortura e justiça social na ditadura. São Paulo: Companhia das Letras, 2001.).

[12] Licia Valladares alinhava algumas hipóteses para explicar por que a família Mesquita, dona do jornal, teria financiado um estudo abrangente sobre favelas do Rio, com duração de três anos, envolvendo um pesquisador estrangeiro. A mais provável, sustentada pelo diretor da pesquisa, José Arthur Rios,é de que os paulistas estavam em busca de argumentos contra a transferência da capital federal para o Cerrado, projeto do então presidente Kubitschek. 
[13] Levantamento do Instituto Pereira Passos, órgão de planejamento da Prefeitura do Rio de Janeiro, mostra que, de 967 trabalhos feitos sobre favelas até 2002, $43 \%$ tiveram 19 favelas delas como objeto. Só a Rocinha teve 82 estudos registrados, seguida do Complexo da Maré, com 75 trabalhos (p.147). ram os dogmas. O mérito do trabalho de Licia Valladares é mostrar como essas várias intervenções, dispersas no tempo, formam parte do imaginário atual, carioca e brasileiro, popular ou erudito sobre o fenômeno.

O ponto com o qual eu gostaria de terminar o comentário a este livro tão importante tem a ver com o caráter de pelo menos um dos três dogmas combatidos por Valladares. Observando a produção recente sobre as favelas cariocas, boa parte resultante de estudos de caso, ${ }^{13}$ é possível levantar a hipótese de que o método esteja influenciando os resultados substantivos das pesquisas, contribuindo para a delimitação das favelas como "comunidades" isoladas. Aqui talvez fosse mesmo o caso de acatar a sugestão final da autora de que as favelas "deixem de ser o campo sistematicamente utilizado para estudar as mais variadas questões ligadas à pobreza" (p. 163). Estudos comparativos da pobreza dentro e fora das favelas talvez contribuíssem para desfazer um dos dogmas a que Valladares se refere. Contudo, não me parece que as ciências sociais do Rio de Janeiro estejam negligenciando o fato de as favelas serem heterogêneas entre si e também internamente. Os textos presentes no livro Um século de favela, organizado por Marcos Alvito e Alba Zaluar e citados pela autora, a tese de doutorado do mesmo Alvito (As cores de Acari), transformada em livro, ou ainda o excepcional $A$ favela fala, organizado por Dulce Pandolvi e Mario Grynszpan no âmbito do Centro de Pesquisa e Documentação de História Contemporânea do Brasil, da Fundação Getulio Vargas (CPDOC/FGV), são apenas alguns exemplos do reconhecimento, por parte da academia, de que a diversidade é uma das marcas do universo das favelas da cidade. Para deixar bem marcada sua posição no interior desse campo de estudos cada vez mais multidisciplinar, Valladares talvez tenha exagerado na delimitação de suas diferenças com relação à produção mais recente. Mas o caráter afirmativo e polêmico das posições da autora, é bom frisar, é outro grande mérito da obra, que se apresenta como contribuição original e, desde logo, de referência.

ADALBERTO CARDOSO é doutor em sociologia pela USP e professor do Instituto Universitário de Pesquisas do Rio de Janeiro (Iuperj). 